\title{
Phaseolin expression in tobacco chloroplast reveals an autoregulatory mechanism in heterologous protein translation
}

\author{
Francesca De Marchis, Michele Bellucci and Andrea Pompa* \\ Research Division of Perugia, Institute of Biosciences and Bioresources, National Research Council, Perugia, Italy
}

Received 3 February 2015;

revised 20 March 2015;

accepted 25 April 2015

*Correspondence (Tel +39075 5014867; fax +39075 5014869;

email andrea.pompa@ibbr.cnr.it)

Keywords: control by epistasy of synthesis, chloroplast transformation, negative feedback, phaseolin, protein folding, protein translation.

\begin{abstract}
Summary
Plastid DNA engineering is a well-established research area of plant biotechnology, and plastid transgenes often give high expression levels. However, it is still almost impossible to predict the accumulation rate of heterologous protein in transplastomic plants, and there are many cases of unsuccessful transgene expression. Chloroplasts regulate their proteome at the post-transcriptional level, mainly through translation control. One of the mechanisms to modulate the translation has been described in plant chloroplasts for the chloroplast-encoded subunits of multiprotein complexes, and the autoregulation of the translation initiation of these subunits depends on the availability of their assembly partners [control by epistasy of synthesis (CES)]. In Chlamydomonas reinhardtii, autoregulation of endogenous proteins recruited in the assembly of functional complexes has also been reported. In this study, we revealed a self-regulation mechanism triggered by the accumulation of a soluble recombinant protein, phaseolin, in the stroma of chloroplast-transformed tobacco plants. Immunoblotting experiments showed that phaseolin could avoid this self-regulation mechanism when targeted to the thylakoids in transplastomic plants. To inhibit the thylakoid-targeted phaseolin translation as well, this protein was expressed in the presence of a nuclear version of the phaseolin gene with a transit peptide. Pulse-chase and polysome analysis revealed that phaseolin mRNA translation on plastid ribosomes was repressed due to the accumulation in the stroma of the same soluble polypeptide imported from the cytosol. We suggest that translation autoregulation in chloroplast is not limited to heteromeric protein subunits but also involves at least some of the foreign soluble recombinant proteins, leading to the inhibition of plastome-encoded transgene expression in chloroplast.
\end{abstract}

\section{Introduction}

Transgene integration into the plastid genome (plastome) is a very promising tool for producing recombinant proteins in plants, and many successful examples have been described (Bock and Warzecha, 2010; Daniell, 2006). In transplastomic plants, foreign proteins can be accumulated in the chloroplast soluble fraction, formed by stroma and thylakoid lumen, or in the chloroplast membranous fraction, composed of thylakoid membranes and envelope. For example, the chloroplast-expressed Arabidopsis inner envelope membrane protein Tic40 has been inserted in the tobacco chloroplast inner envelope (Singh et al., 2008), while other proteins are targeted to thylakoid membranes (Ahmad et al., 2012; Shanmugabalaji et al., 2013). Sorting foreign polypeptides to the tobacco thylakoid lumen improve their accumulation, like the bacterial alkaline phosphatase (Bally et al., 2008) or a camelid antibody fragment (Lentz et al., 2012), but the most abundant proteins expressed in transformed chloroplasts are all accumulated in the stroma. Examples of this recombinant protein hyperexpression include an insecticidal toxin expressed at $46 \%$ of the plant's total soluble proteins (TSPs) (De Cosa et al., 2001), or a proteinaceous antibiotic expressed at $>70 \%$ of the plant's TSPs (Oey et al., 2009). However, up to now, it is almost impossible to predict the accumulation rate of heterologous protein in transplastomic plants (Bock, 2014).
Indeed, in several cases, the expression level of recombinant proteins in the transplastomic plants appears to be very poor (Bellucci et al., 2005; Birch-Machin et al., 2004; Wirth et al., 2006). It is well known that over evolutionary time most of the chloroplast genes have been either eliminated or transferred to the nucleus of the host cell, so today a highly integrated modulation between the nucleus and the plastome is needed in cell development (Timmis et al., 2004; Woodson and Chory, 2008). This coordinate expression in chloroplasts takes place mainly through translational regulation, which is a major feature of plastome gene expression, and the expression of heterologous genes inserted into the plastome is also mainly regulated by posttranscriptional mechanisms (De Marchis et al., 2012; Manuell et al., 2007; Tiller and Bock, 2014). However, accumulation of plastome-encoded foreign protein requires several key steps including rate of transcription, translation and protein stability (Scotti et al., 2013). Many studies conducted with chimeric gene fusions have identified combinations of promoters, 5'-UTRs and 3'-UTRs, which can be used to achieve a high level of recombinant protein expression in chloroplasts, regulating transcript stability and translatability (Tangphatsornruang et al., 2011; Yang et al., 2013). In addition, the $\mathrm{N}$-terminal sequence of recombinant proteins expressed in the chloroplasts is a key factor for both mRNA stability/translatability (Kuroda and Maliga, 2001) and protein stability (Ye et al., 2001). Unfortunately, there 
are no precise rules for the best performing sequences, and empiric attempts have to be made. For example, Elghabi et al. (2011) have fused $\mathrm{N}$-terminal segments of highly expressed proteins in plastids to the transgene coding region, stabilizing the cyanovirin-N mRNA. In other cases, significant accumulation of foreign proteins has been achieved fusing an 11.6-kDa N-terminal cholera toxin B subunit (CTB) to therapeutic proteins (Kwon et al., 2013). Proteins fused to CTB have various accumulation levels, from $1 \%$ to $70 \%$ of total leaf protein (Kwon et al., 2013; Ruhlman et al., 2010), and the sole removal of a protease cleavage site between CTB and coagulation factor IX has enhanced fusion protein accumulation by 20 -fold (Verma et al., 2010). In spite of the similarity to its prokaryotic ancestors of the gene expression machinery, regulation of translation in the chloroplast results to be more complex than in bacteria and it is ensured, for example by many nucleus-encoded RNA-binding translational factors (Barkan and Small, 2014; Stern et al., 2010). Furthermore, the subunits of multiprotein complexes, formed by both nuclear-encoded and plastome-encoded proteins, reveal a mechanism in which the translation rate of plastome-encoded proteins is self-regulated by the availability of their assembly partners. This process, called control by epistasy of synthesis (CES), has been described in tobacco and maize, as well as in senescent rice leaves, for Rubisco large subunit (LS) synthesis, which depends on the presence of its assembly partner Rubisco small subunit (Suzuki and Makino, 2013; Wostrikoff and Stern, 2007; Wostrikoff et al., 2012). Also in Arabidopsis, a CES process may regulate synthesis of the PSII protein CP47 (Levey et al., 2014). It is not yet clear whether autoregulatory mechanisms in plants represent a general feature of chloroplast gene expression like in Chlamydomonas reinhardtii (Zoschke et al., 2013), where CES regulates the synthesis of PSII, PSI, cytochrome $b_{6} f$ and $\mathrm{H}^{+}$ATP synthase proteins (Boulouis et al., 2011; Drapier et al., 2007; Minai et al., 2006; Wostrikoff et al., 2004). However, it should be considered that chloroplast gene expression in C. reinhardtii is different from that in plants in many aspects. For example, with a multisubunit plastid-encoded RNA polymerase present in both C. reinhardtii and plants, no nucleus-encoded plastid RNA polymerase seems to exist in C. reinhardtii whereas it has been additionally present in plant plastids (Shiina et al., 2005). Moreover, foreign protein levels in this alga chloroplast are generally an order of magnitude lower than in plants (Michelet et al., 2010). Translational autoregulation processes similar to CES have been reported in prokaryotic and other eukaryotic systems (Fontanesi et al., 2010). In the bacterium Borrelia burgdorferi, for example, the Bpur polypeptide is able to interact with the $5^{\prime}$ region of its own mRNA, thereby inhibiting translation (Jutras et al., 2013;)

Protein stability is often the key aspect that determines foreign protein accumulation in transplastomic plants (Elghabi et al., 2011), but other factors can be the cause of poor or undetectably low expression levels of heterologous polypeptides in these plants. Our study aimed to understand whether, in transplastomic plant chloroplasts, translational autoregulation mechanisms can be described even for at least some of the foreign soluble stromal proteins not involved in the formation of large heteromeric protein complexes. We previously tried to overexpress in transplastomic plants a recombinant protein, termed zeolin (De Marchis et al., 2011b), which could be fused to proteins of biotechnological interest to enhance their accumulation (de Virgilio et al., 2008). Zeolin is a chimeric polypeptide composed of the bean seed protein phaseolin with or without its own signal peptide for ER lumen targeting (Frigerio et al., 1998; Vitale et al.,
1995), fused to a maize $\gamma$-zein domain. Unfortunately, the synthesis of zeolin, when expressed without its signal peptide in the chloroplast stroma, was strongly inhibited, whereas the same protein with the $\mathrm{N}$-terminal signal peptide was transported to the thylakoid compartment and accumulated there to a much higher extent (De Marchis et al., 2011b). This last result confirmed the previous reports, which demonstrated that signal peptides could target to thylakoids recombinant proteins expressed by transformed chloroplasts (Bally et al., 2008; Hennig et al., 2007). We observed that zeolin was subjected to partial fragmentation at the junction between the phaseolin and the zein portions in tobacco transplastomic plants (Bellucci et al., 2007). Therefore, to investigate the reason for zeolin synthesis inhibition in the chloroplast stroma, we generated several tobacco plants transformed in the nucleus, in the plastome or in both genomes of supertransformed plants, with a phaseolin gene, with or without its signal peptide, which codes for the $\mathrm{N}$-terminal zeolin portion. We discovered that in supertransformed plants phaseolin mRNA translation was inhibited due to the accumulation in the stroma of the same soluble protein imported from the cytoplasm and that phaseolin could avoid this autoregulation mechanism when targeted to the thylakoids in transplastomic plants. These results show the existence of negative feedback acting at the level of heterologous protein accumulation in the plant chloroplast. Indeed, phaseolin does not take part in the formation of heteromeric protein complexes into the chloroplast; hence, negative feedback seems not to be limited to the CES process, which concerns endogenous proteins involved in the formation of heteromeric complexes.

\section{Results}

\section{Expression of different phaseolin genes in tobacco chloroplasts and analysis of phaseolin polypeptides folding}

To prove the existence of a mechanism that controls the accumulation of plastome-encoded foreign proteins by negative feedback, we generated transplastomic tobacco plants expressing plastome-inserted transgenes' coding for phaseolin both with $(P)$ and without its $\mathrm{N}$-terminal signal peptide $(\Delta \mathrm{P})$. The accumulation of these two proteins in tobacco transformants was verified in Western blots with antiphaseolin antiserum (Figure 1a). The signal intensity of the 46-kDa bands corresponding to the two phaseolin forms was quantified indicating that $\mathrm{P}$ accumulated almost a hundred times more than $\Delta \mathrm{P}$ in the chloroplast. However, the low $\Delta P$ accumulation was not attributable to a defect in the transcription of its gene as demonstrated by northern blotting analysis on the same two transplastomic plants in Figure 1a. Following hybridization with an antiphaseolin probe, three phaseolin-encoding transcripts were detected (monocistronic phaseolin, dicistronic aadA/phaseolin and polycistronic 16S/trnl/aadA/phaseolin), as previously described (Bellucci et al., 2007). Moreover, there were comparable recombinant mRNA levels between plants transformed with $\mathrm{P}$ or $\Delta \mathrm{P}$ constructs (Figure $1 \mathrm{~b}$ ). The failure of $\Delta \mathrm{P}$ accumulation inside tobacco chloroplast could be due to an intense proteolytic activity towards this protein; therefore, we generated nuclear-transformed tobacco plants expressing a phaseolin variant $(\mathrm{t} p \Delta \mathrm{P})$ with a C-terminal FLAG tail, in which the signal peptide had been replaced by the tobacco Rubisco small subunit (SS) transit peptide, which directed the protein into the chloroplast. The correct plastidial localization of $\operatorname{tp} \Delta \mathrm{P}$ was confirmed through immunofluorescence experiments (Fig- 

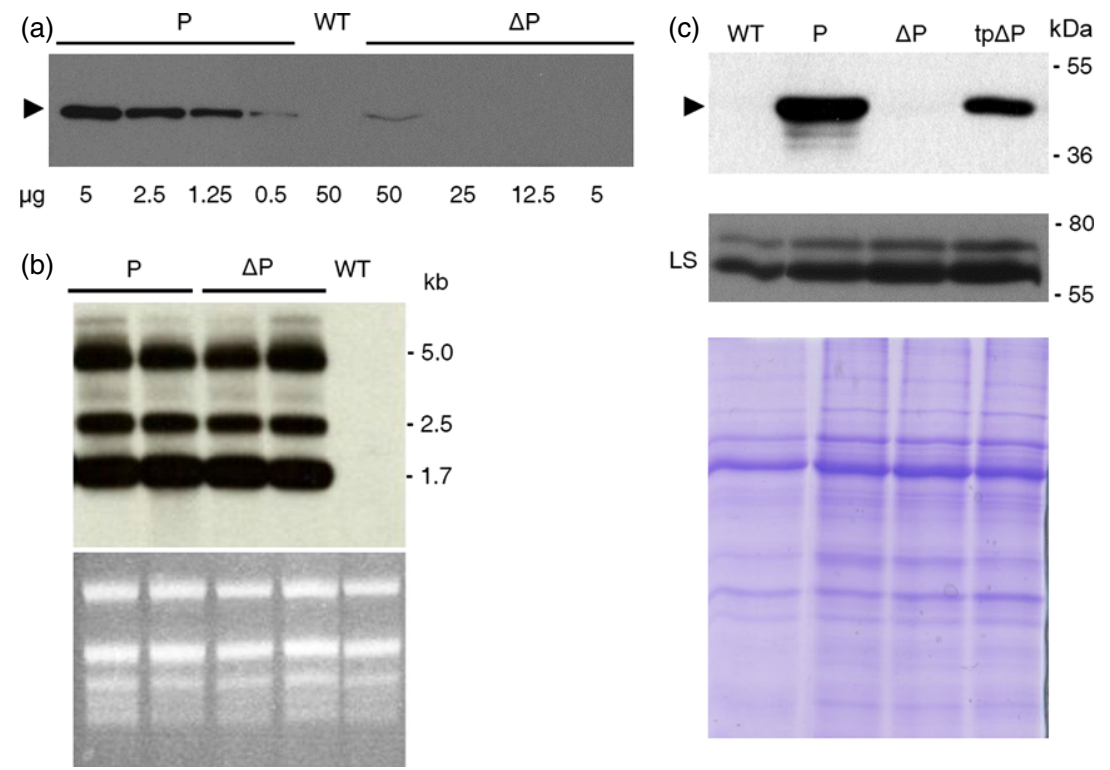

Figure 1 Transcription and protein accumulation of different phaseolin genes in tobacco chloroplasts. (a) Total proteins extracted from leaves of a WT plant, or transplastomic plants expressing $\mathrm{P}$ or $\Delta \mathrm{P}$, were analysed by SDS-PAGE and Western blotting using antiphaseolin antiserum. The arrowhead marks the position of mature phaseolin, and $\mu \mathrm{g}$ stands for total protein extract. (b) Northern blot analysis was performed on total RNA extracted from $P$, $\triangle \mathrm{P}$ and WT plants and hybridized with the phaseolin gene. Numbers at right indicate molecular mass markers in kb. rRNA stained by ethidium bromide is shown as a loading control. (c) Eight micrograms of total proteins extracted from leaves of a WT plant, transplastomic plants expressing $\mathrm{P}$ or $\Delta \mathrm{P}$, or phaseolin with a transit peptide (tp $\Delta \mathrm{P})$ was separated by SDS-PAGE and immunoblotted with antiphaseolin or anti-Rubisco large subunit (LS) antiserum. The arrowhead marks the position of mature phaseolin. Protein stained by Coomassie is shown as a loading control. Numbers at right indicate molecular mass markers in $\mathrm{kDa}$.

ure S1). tp $\Delta \mathrm{P}$ was synthesized on cytoplasmic ribosomes and then imported into the chloroplast, where the cleavage of the transit peptide originated a polypeptide virtually identical to the $\Delta \mathrm{P}$ expressed by the transplastomic tobacco plant and synthesized on plastid ribosomes. We postulated that if the chloroplast proteolytic degradation specifically limited $\Delta \mathrm{P}$ accumulation instead of $\mathrm{P}$ accumulation the amount of tp $\Delta \mathrm{P}$ protein detected inside the chloroplast should have been much lower than the amount of $\mathrm{P}$ accumulated in the same organelle. Conversely, as the amount of $\operatorname{tp} \Delta P$ was roughly $1 / 3-1 / 5$ of that of $P$ (Figure 1C, upper panel), there should have been other reasons for the large reduction of $\Delta \mathrm{P}$ accumulation in chloroplast. A possible cause of the low accumulation of $\Delta \mathrm{P}$ protein could be ascribed to a general decrease in chloroplast proteins' synthesis. To exclude this possibility, the same samples were analysed for both the content of the endogenous plastid protein Rubisco large subunit (LS) (Figure 1c, middle panel), and for total protein content (Figure 1c, lower panel). We can conclude from these results that there was not a decrease in proteins synthesis. The difference in the accumulation of the two phaseolin forms might find the reason in $\Delta \mathrm{P}$ polypeptide instability caused by an alteration in protein folding. To verify this hypothesis, the three-dimensional conformation of $\mathrm{P}$ and $\Delta \mathrm{P}$ was examined. When properly folded, phaseolin assembled in the endoplasmic reticulum (ER) into homotrimers which, being resistant to in vitro trypsin digestion, produced 20- to $30-\mathrm{kDa}$ peptide fragments that did not undergo further degradation (Deshpande and Nielsen, 1987; Pompa et al., 2010). In Figure 2a, total leaf proteins extracted from tobacco plants expressing the two chloroplast phaseolin forms, or a nuclear-encoded phaseolin (Pnu) translocated into the ER lumen, were subjected to trypsin digestion followed by an immunoblot analysis with antiphase- olin antiserum. All the plants produced 18- to 30-kDa peptide fragments suggesting that phaseolin polypeptides were properly folded. In particular, while the Pnu control digestion showed several fragments of $18-22 \mathrm{kDa}$, chloroplast $\mathrm{P}$ and $\Delta \mathrm{P}$ showed a quite similar resistant fragment profile after trypsin treatment, with a 25-kDa fragment and a 18-kDa doublet (Figure 2a). Indeed, the intensity difference of the $18-\mathrm{kDa}$ doublet between $\mathrm{P}$ and $\Delta \mathrm{P}$ did not mean a difference in protein conformation because in other trypsin digestions the intensity of this $18-\mathrm{kDa}$ doublet was almost identical. Furthermore, the proper achievement of the homotrimeric three-dimensional structure was also confirmed by sucrose sedimentation velocity gradient experiments (Figure $2 \mathrm{~b}$ ). These show that $\Delta \mathrm{P}$ polypeptides had the same peak of migration of the Pnu trimers (phaseolin molecular weight $46 \mathrm{kDa} \times 3=138 \mathrm{kDa}$ ), whereas $\mathrm{P}$ migrated as trimers and oligomers constituted by the association of two or more trimers. These results demonstrated that $\Delta \mathrm{P}$ low expression did not originate by its unfolded status.

\section{Accumulation of plastome-encoded phaseolins depends on their intraplastidial localization}

We also investigated the effect of intraplastidial localization on $\mathrm{P}$ and $\Delta \mathrm{P}$ accumulation. Purified chloroplasts were fractionated into the thylakoid and stroma compartments and subjected to immunoblot experiments with antiphaseolin antiserum. P was almost completely recovered in the thylakoid fraction, whereas $\Delta \mathrm{P}$ was present in both thylakoid and stromal fractions, albeit to a greater extent in the first one (Figure 3a). To verify whether $\mathrm{P}$ and $\Delta \mathrm{P}$ were inserted in the thylakoid fraction or only associated with it, thylakoids were subjected to sequential washes with different saline concentration buffers. While $\Delta \mathrm{P}$, already detached from thylakoids after the first wash with an 


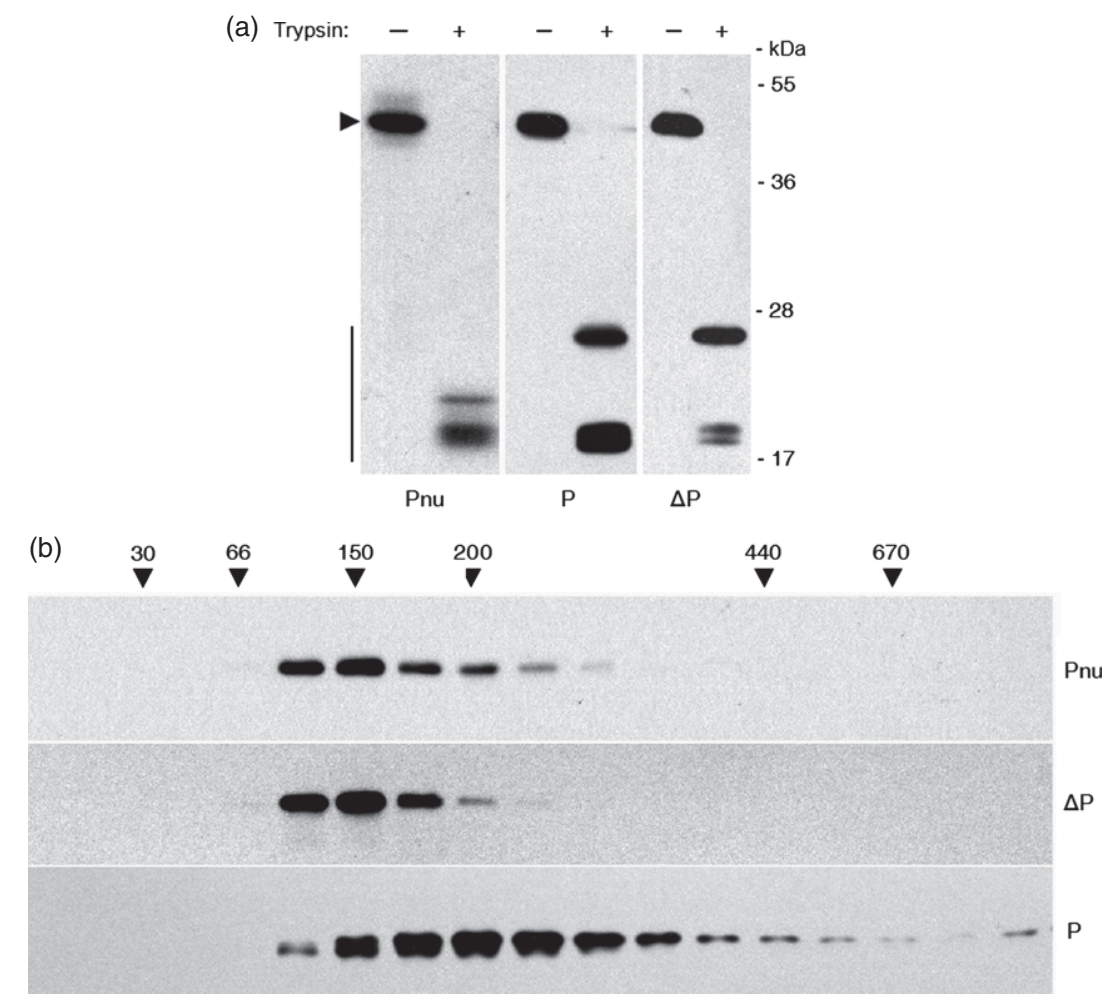

Figure 2 Three-dimensional conformation of $\mathrm{P}$ and $\Delta \mathrm{P}$ phaseolins in the chloroplast. (a) Total leaf proteins extracted from nuclear-transformed plants expressing the entire phaseolin (Pnu, protein aliquots of $8 \mu \mathrm{g}$ ), as a positive control for trypsin assay, and from transplastomic plants expressing $P$ (protein aliquots of $8 \mu \mathrm{g}$ ) or $\Delta \mathrm{P}$ (protein aliquots of $40 \mu \mathrm{g}$ ) were subjected to trypsin digestion in vitro for 30 min or incubated without enzyme. Protein samples were then analysed by SDS-PAGE and Western blotting using antiphaseolin antiserum. The arrowhead marks the position of intact phaseolin, while vertical bar marks the trypsin-resistant phaseolin fragments. Numbers at right indicate molecular mass markers in $\mathrm{kDa}$. (b) The same proteins extracted from (a) were fractionated by centrifugation on velocity sucrose gradient. A leaf homogenate aliquot of $0.12 \mathrm{~mL}$ was loaded on the sucrose gradient, whereas $0.60 \mathrm{~mL}$ of leaf homogenate was loaded for the $\Delta \mathrm{P}$ sample due to the low transgene expression of this transplastomic line. Different fractions were collected, and each fraction was analysed by SDS-PAGE and Western blotting using antiphaseolin antiserum. Numbers on top indicate molecular mass, in $\mathrm{kDa}$, of sedimentation markers. Protein blots in (a) and (b) were exposed to different times (a few seconds for the Pnu and $\mathrm{P}$ samples and a few minutes for the $\Delta \mathrm{P}$ sample).

isotonic solution (WB), was completely removed by the addition of a highly concentrated saline buffer $(\mathrm{NaCl}), \mathrm{P}$ remained strictly associated with thylakoid membranes without being affected by these treatments (Figure $3 b$ ). This demonstrated that $\Delta \mathrm{P}$ was only weakly associated with the thylakoids, whereas $P$ was likely inserted into the thylakoid lipid bilayer or translocated into the thylakoid lumen, with its signal peptide removed after the insertion/translocation (Figure 3c). Thus, the localization of $P$ in the thylakoids and its high accumulation level in comparison with $\Delta P$ (Figure 1a) suggest that $\Delta P$ localization to the stromal side of thylakoids could lead to its low accumulation. To understand whether the presence in the stroma per se was a sufficient condition for $\Delta \mathrm{P}$-reduced expression, we verified whether the chloroplast-imported mutant of phaseolin, $\mathrm{tp} \Delta \mathrm{P}$, after the transit peptide removal, was recovered in the stroma as expected. Total proteins from leaves of transgenic $\operatorname{tp} \Delta \mathrm{P}$ and transplastomic $\mathrm{P}$ plants were separated in two fractions containing the soluble- and the membrane-associated polypeptides. Proteins recovered in the soluble fraction (Figure 3d, Sol) were extracted with a buffer containing a high $\mathrm{NaCl}$ concentration which, as shown in Figure $3 b$, was not able to solubilize the integral membrane proteins. Intrinsic thylakoid polypeptides were then extracted from the pelleted membranous fraction with a buffer containing Triton X-100 as detergent (Figure 3d, Pel). Both the stromal control Rubisco LS and the thylakoid control CP47 were localized in the soluble or membranous fractions, respectively. The results showed that tp $\Delta \mathrm{P}$ was a soluble stromal protein; on the contrary $P$, as expected, was strictly associated with the membranes or translocated into the thylakoid lumen (Figure $3 d$ ). As tp $\Delta \mathrm{P}$ synthesized in the cytoplasm possessed the same stromal localization of $\Delta \mathrm{P}$ but an accumulation level almost comparable to that of $P$, the logical reason for the big difference in $\mathrm{P}$ and $\Delta \mathrm{P}$ accumulation must be found in the mechanism regulating their mRNA translation or protein synthesis in the stroma.

\section{Phaseolin synthesis in chloroplast is repressed at the translational level by an autoregulation mechanism}

The regulation of the expression of the plastome transgenes' coding for $\mathrm{P}$ and $\Delta \mathrm{P}$ was investigated at the translational level by pulse-chase experiments with radioactive amino acids. With this technique, it was possible to monitor the synthesis of a protein in the unit of time along with its half-life. Protoplasts isolated from $\mathrm{P}$ 
(a)

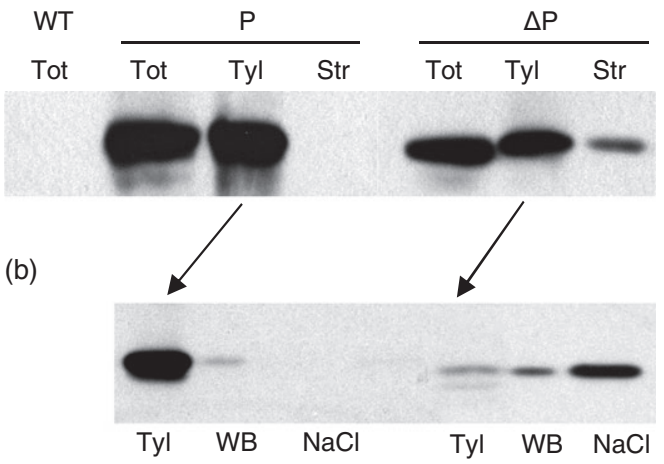

(c)

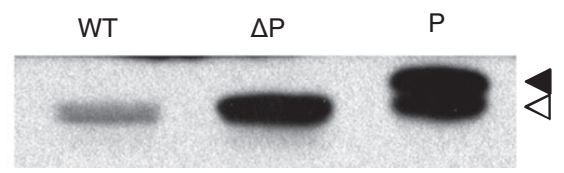

(d)

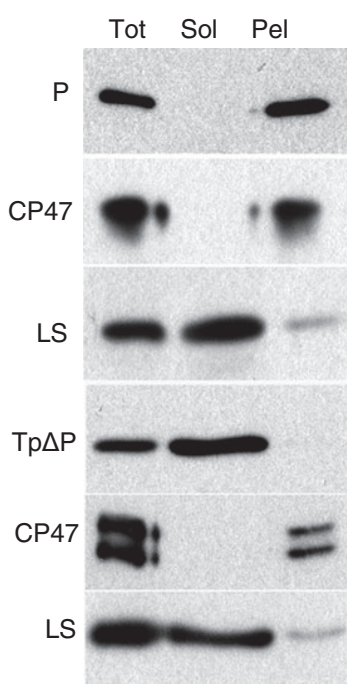

Figure 3 Subplastidial localization of $\mathrm{P}, \Delta \mathrm{P}$ and $\mathrm{tp} \Delta \mathrm{P}$. (a) Sucrose-purified chloroplasts derived from transplastomic plants expressing $\mathrm{P}$ and $\Delta \mathrm{P}$ proteins were fractionated into stroma (Str) and thylakoid fractions (Tyl). (b) The thylakoid fractions of (a) were subjected to two sequential washes with an isotonic buffer (WB) and then with a saline buffer containing $2 \mathrm{~m} \mathrm{NaCl}$. To increase the $\Delta \mathrm{P}$ signal intensity, $20 \mu \mathrm{g}$ of protein was loaded in the stromal sample (while $2 \mu \mathrm{g}$ of protein was loaded for the P sample), and $5 \mu \mathrm{g}$ of chlorophyll was loaded in the Tot and Tyl samples (while $0.5 \mu \mathrm{g}$ of protein was loaded for the P sample). (c) Cleavage of the phaseolin signal peptide in chloroplast. Proteins extracted from young leaves of a WT plant and transplastomic plants expressing $\triangle \mathrm{P}$ and $\mathrm{P}$ were analysed by SDS-PAGE and Western blotting with antiphaseolin antiserum. The gel was run for a time longer than that in Figure 1a to separate the entire phaseolin from phaseolin without the signal peptide. Black arrowhead indicates the entire phaseolin polypeptide, and empty arrowhead indicates phaseolin without signal peptide. (d) Proteins, extracted from lysed leaves and homogenated with a saline buffer supplemented with $2 \mathrm{~m} \mathrm{NaCl}$, were separated in two fractions: the soluble (including stromal) proteins and the integral membrane (including thylakoids) proteins. Samples were analysed by immunoblot using antibodies against phaseolin, CP47 and LS. The CP47 antibody detected a doublet signal in the tp $\Delta \mathrm{P}$ plant sample that in the $\mathrm{P}$ plant sample is not resolved due to short run of the SDS-PAGE. While $2 \mu \mathrm{g}$ of protein was loaded in the stromal samples, $0.5 \mu \mathrm{g}$ of chlorophyll was loaded in the Tot and Tyl samples. All protein blots were exposed few seconds to decrease the background signals.

and $\Delta \mathrm{P}$ transplastomic tobacco plants were pulse-labelled for $1 \mathrm{~h}$ and chased for the indicated periods of time. Protoplasts were homogenated, immunoprecipitated with the antiphaseolin antiserum and analysed by SDS-PAGE and fluorography. The $P$ protein was detected at the pulse and displayed a half-life of about $4 \mathrm{~h}$. Conversely, it was impossible to detect $\Delta \mathrm{P}$, likely because this protein was under the detection limit of the experiment (Figure 4a). To rule out that a rapid degradation of newly synthesized $\Delta \mathrm{P}$ protein makes it impossible to be detected, the same experiment was carried out by decreasing the pulse to 15 min, obtaining the same result. Moreover, no phaseolin polypeptide was detected in the supernatant fractions recovered after protoplast immunoprecipitation and subjected to a second round of immunoprecipitation with the same antibody (data not shown). The translation activity of these two genes was further investigated using polysome analysis (Figure 4b). Extracts from $P$ and $\Delta \mathrm{P}$ transplastomic leaves were fractionated in sucrose density gradients, with and without EDTA, and analysed by northern blotting experiments with a phaseolin probe. EDTA treatment released associated ribosomes from mRNAs, and comparison between EDTA-containing and EDTA-free gradient samples allowed us to determine the monosome- versus polysomecontaining fractions. A difference in polysome loading was detected between $\mathrm{P}$ and $\Delta \mathrm{P}$ transplastomic plants, suggesting that the corresponding genes' translation had been not carried out with comparable efficiency. P mRNA was prevalently associated with actively translating polysomes (Figure $4 b$, sample $P$, lanes 6-8), while $\triangle \mathrm{P}$ mRNA was poorly translated because it was largely detected in the top fractions of the gradient (Figure $4 b$, sample $\Delta P$, lanes $3-5$ ). These results revealed a significant reduction in $\triangle \mathrm{P}$ mRNA translation activity.

To understand the mechanism regulating $\triangle \mathrm{P}$ mRNA translation, we hypothesized that in the chloroplast stroma $\Delta \mathrm{P}$ protein would repress its own translation with an autoregulation mechanism. In this hypothetic case, the P protein could escape this self-regulation because its signal peptide mediated the rapid translocation into the thylakoid compartment, subtracting $P$ polypeptides from the stroma. Thus, we increased the abundance of a phaseolin protein in the stroma of transformed chloroplasts to trigger $P$ autoregulation. A transplastomic P plant was supertransformed with the nuclear $\operatorname{tp} \Delta \mathrm{P}$ construct, and the resulting plants were named supertransformants (SupT). The SupT plants were analysed for the presence of both nuclear and plastidial phaseolin genes by PCR, and for the resistance to both kanamycin and spectinomycin, which were used for the two different transformation events' selection (Figure S2). While the plastome-encoded P could be visualized only with the antiphaseolin antiserum, the nuclearencoded tp $\Delta \mathrm{P}$ protein was $\mathrm{C}$-terminal Flag-tagged, thus detectable with both anti-Flag and antiphaseolin antibodies. To assess the relative amount of the two phaseolin polypeptides in SupT plants, total leaf proteins from tobacco tp $\Delta P, P$ and SupT transformants were separated, as described in Figure $3 d$, into soluble and membranous fractions and subjected to SDS-PAGE followed by Western blot analysis with anti-Flag or antiphaseolin 
(a)

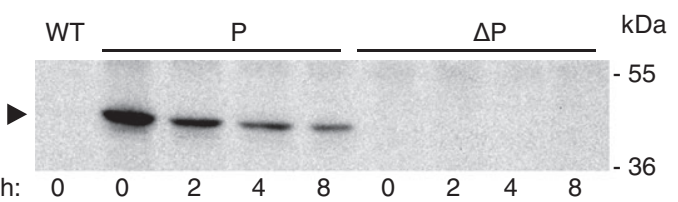

(b)
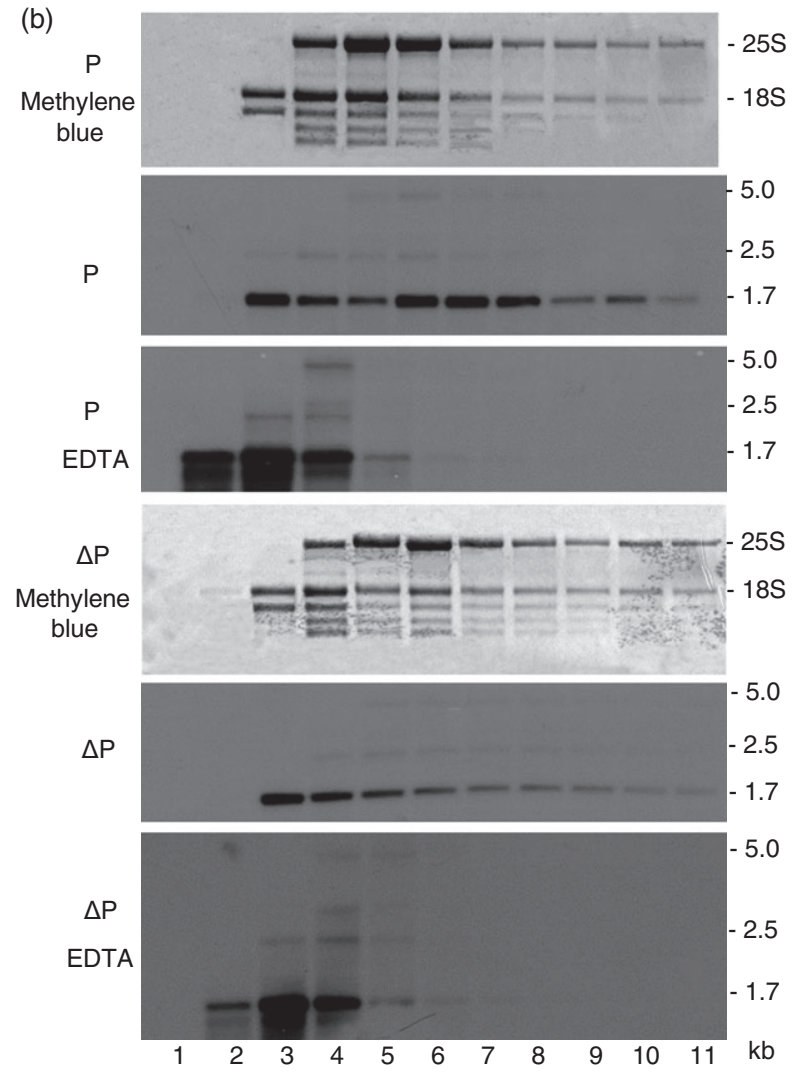

Figure 4 Modulation of $\mathrm{P}$ and $\Delta \mathrm{P}$ synthesis in chloroplasts. (a) Protoplasts from transplastomic $\mathrm{P}$ and $\Delta \mathrm{P}$ tobacco plants were pulse-labelled for $1 \mathrm{~h}$ and chased for the indicated periods of time. Homogenated cells were immunoprecipitated with antiphaseolin antiserum and analysed by SDSPAGE and fluorography. Black arrowhead indicates phaseolin polypeptide. Numbers at right indicate molecular mass markers in $\mathrm{kDa}$. (b) Polysome analysis was performed from leaves of $\mathrm{P}$ and $\Delta \mathrm{P}$ plants following sedimentation through a $15 \%-55 \%$ sucrose gradient, with or without EDTA. Methylene blue staining is used to visualize the ribosomal RNA fractionation profile for the samples without EDTA, while the methylene blue staining for the samples with EDTA is not shown. An equal proportion of RNA isolated from each fraction was analysed by northern blot with the phaseolin probe. Numbers at right indicate molecular mass markers in $\mathrm{kb}$.

antisera. The anti-Flag antibody, in both tp $\Delta \mathrm{P}$ and SupT plants, detected almost all the $\mathrm{t} p \Delta \mathrm{P}$ protein in the soluble fraction except for a small amount detected in the membranous compartment, which could also be due to the contamination by the stroma as judged by the use of an anti-LS antibody (Figure 5a, upper and lower panel). As expected, no signal was shown with anti-Flag antibody in the P transplastomic plant. The use of the antiphaseolin antiserum in the same plant samples allowed us to reveal both $\mathrm{P}$ and tp $\Delta \mathrm{P}$ polypeptides. In this case, as in Figure $3 \mathrm{~d}$, in $\mathrm{P}$ plants the protein was mostly recovered in the pellet containing the thylakoid membranes (Figure 5a, middle panel). Assuming that SupT plants should express the same amount of plastidial phaseolin of the original transplastomic plant, we expected to
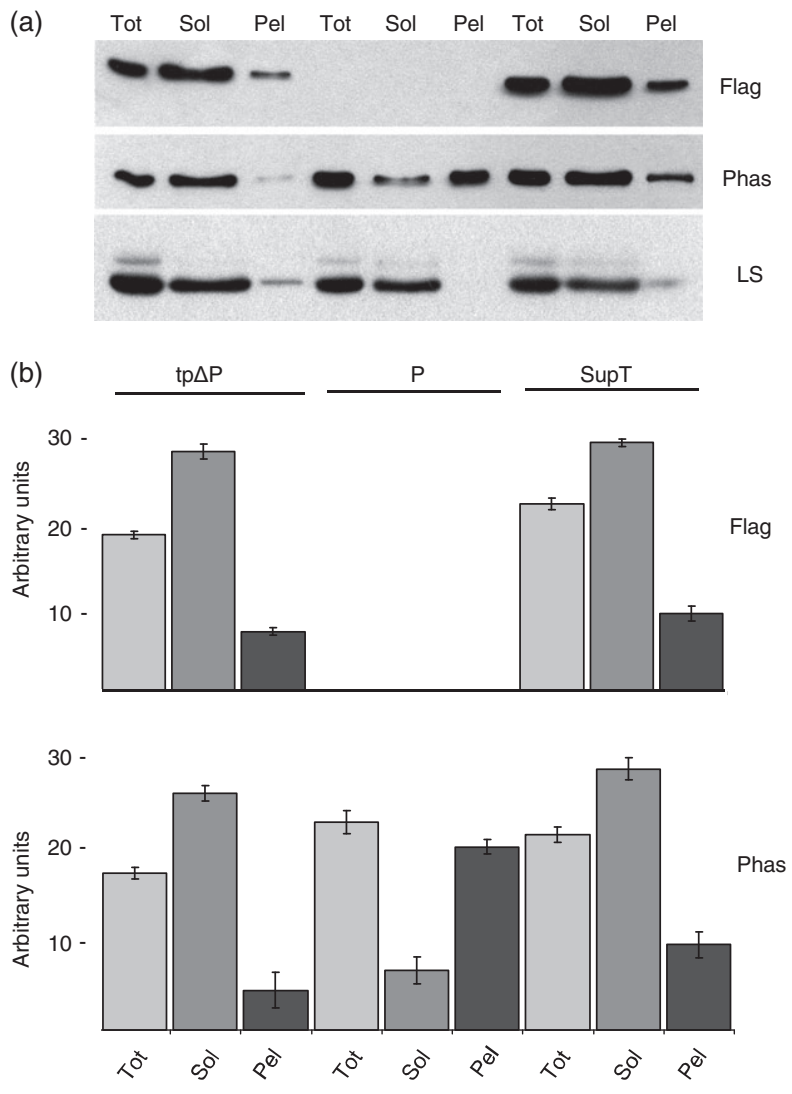

Figure 5 Comparison of relative phaseolin amounts in soluble and membrane fractions in $\mathrm{P}, \mathrm{tp} \Delta \mathrm{P}$ and supertransformants (SupT) tobacco plants. (a) Total proteins (Tot) from tp $\Delta \mathrm{P}, \mathrm{P}$ and SupT tobacco plants were separated with a saline buffer $(2 \mathrm{M} \mathrm{NaCl})$ in soluble (Sol) and integral membrane proteins (Pel) as in Figure 3d, then analysed by immunoblot using antibodies against FLAG, phaseolin and LS. (b) Quantitative analysis of phaseolin proteins detected by immunoblot in (a). Error bars represent the standard deviation calculated for each chloroplast fraction derived from three independent measurements per fraction using anti-Flag or antiphaseolin antibodies.

recover in the SupT membranous fraction (Pel) at least the identical amount of phaseolin polypeptide detected in same fraction of $\mathrm{P}$ plant. On the contrary, the amount of phaseolin measured on the SupT membranes was roughly less than half of that measured in P membranes (Figure 5b), suggesting that in SupT the contribution given by $\mathrm{P}$ protein on the whole phaseolin content is reduced with respect to the nuclear-encoded tp $\Delta \mathrm{P}$. Consequently, the total amount of phaseolin detected in the SupT samples was almost entirely located into the soluble fraction, and it was likely attributable to the sole contribution of $\operatorname{tp} \Delta \mathrm{P}$. These data suggested that P protein was no longer present in the SupT fraction containing the thylakoid membranes.

Two hypotheses were formulated to explain the fate of the plastome-encoded P protein in the SupT plants: the protein could have been relocated in the stroma, or its synthesis could have been strongly inhibited. To verify these last assumptions, we performed both sucrose sedimentation velocity gradient experiments and pulse-chase assays. The sucrose gradient confirmed that in SupT plant the large part of phaseolin was likely constituted by trimeric tp $\Delta \mathrm{P}$ polypeptides, whereas $\mathrm{P}$ trimers and oligomers were a minor fraction of the total phaseolin polypeptides (Figure S4). The pulse-chase experiments were 
performed in the presence of the cytosolic protein synthesis inhibitor cycloheximide (CHX) (Figure 6). This allowed us to unveil whether the production of $\mathrm{P}$ synthesized in the stroma had really been suppressed in SupT plants. Protoplasts isolated from the three transformed plants $t p \Delta P, P$ and SupT were pulse-labelled for $1 \mathrm{~h}$, in the presence or absence of $\mathrm{CHX}$, and then immunoprecipitated with antiphaseolin antibody and analysed by SDSPAGE and fluorography (Figure 6a). To verify that all the radioactive-labelled phaseolin polypeptides were immunoprecipitated after the pulse-chase, the supernatant fractions derived from the previously described immunoprecipitation were subjected to a second round of immunoprecipitation with the same antibody and then analysed in the same way, but they did not show any presence of phaseolin polypeptides (Figure S3). In tp $\Delta P$ plants, in the presence of $\mathrm{CHX}$, phaseolin is not recovered after immunoprecipitation because this drug inhibited $\operatorname{tp} \Delta \mathrm{P}$ synthesis in the cytoplasm (Figure 6a, lanes 1-2). CHX should not have inhibited translation on plastid ribosomes, but an approximate reduction of $50 \%$ of the phaseolin synthesized by transplastomic $P$ plants was observed, possibly due to drop in the amount of some nuclear-encoded factors targeting the psbA 5'UTR that are required for D1 expression (Figure 6a, lanes 3-4). The total amount of phaseolin recovered after immunoprecipitation from SupT protoplasts was bigger (Figure 6a, lane 5) than the phaseolin present in $\mathrm{tp} \Delta \mathrm{P}$ and $\mathrm{P}$ protoplasts (Figure 6a, lanes 1 and 3), but it disappeared in the presence of $\mathrm{CHX}$ (Fig 6a, lane 6). As phaseolin loading control, an immunoblot analysis with an

(a)

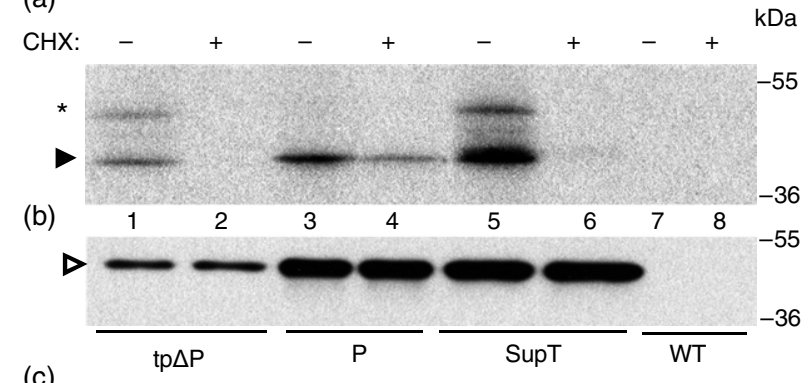

(c)

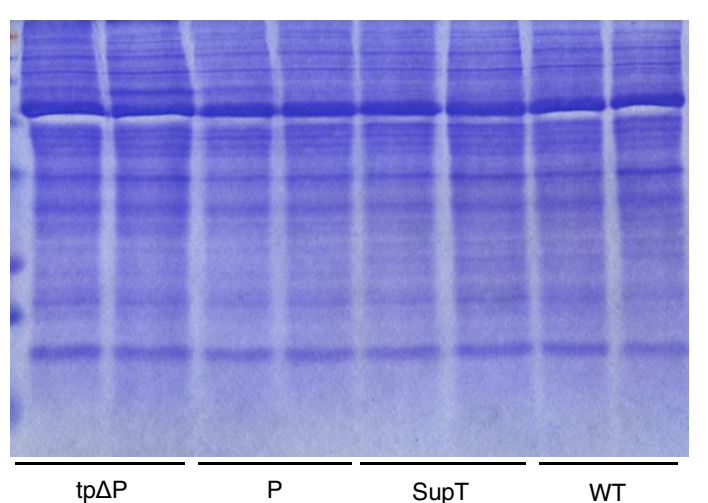

Figure 6 Repression of P synthesis in supertransformants (SupT) tobacco plants. Protoplasts from leaves of a WT plant, or from transformed tobacco plants expressing tp $\Delta \mathrm{P}, \mathrm{P}$ and SupT proteins, were pulse-labelled for $1 \mathrm{~h}$ in the presence or absence of cycloheximide $(\mathrm{CHX})$. An equal number of homogenated protoplasts were immunoprecipitated (a) or detected by immunoblot (b), with antiphaseolin antiserum. (c) Protein stained by Coomassie is shown as a loading control of (b). Black arrowhead indicates radiolabelled phaseolin polypeptide, empty arrowhead indicates phaseolin and asterisk refers to the entire tp $\Delta \mathrm{P}$ protein with the transit peptide not yet cleaved. antiphaseolin antibody was performed on total proteins extracted from the same number of pulse-labelled protoplasts used for the immunoprecipitation (Figure 6b, c). In this way, all the phaseolins immunoprecipitated from SupT protoplasts was synthesized in the cytosol. This strongly suggested that, in SupT transformants, the presence of $\operatorname{tp} \Delta \mathrm{P}$ in the stroma repressed the $\mathrm{P}$ synthesis. Therefore, the regulation of the plastidial $P$ expression occurred at the translational level, as already seen for $\Delta \mathrm{P}$ in the transplastomic plants (Figure 4b). To verify this hypothesis, an analysis on polysomes extracted from $\mathrm{P}, \Delta \mathrm{P}$ and SupT tobacco leaves was performed with the phaseolin signal peptide sequence as radioactive probe. This probe was able to discriminate between the two phaseolin mRNAs of the SupT plants, because the $P$ mRNA would be hybridized, whereas tp $\triangle \mathrm{P}$ mRNA would not due to the lack of the signal peptide sequence in the corresponding gene. In the same way, the P mRNA of the P plants, used as positive control, would be hybridized to this probe, but no signal would result from the $\triangle \mathrm{P}$ mRNA in $\triangle \mathrm{P}$ plants, used as negative control. There was a shift in polysome association of the $P$ mRNA with the top fractions of the sucrose gradient when the SupT plant (Figure 7, sample SupT, lanes 4-5) was compared with the P plant. Thus, the translation efficiency of the P mRNA was reduced in SupT plants in comparison with the P transformants, where the same transcript was mostly polysomal associated (Figure 7, sample $P$, lanes 6-8 and Figure $4 \mathrm{~b}$ ). As expected, no signal was visualized in $\Delta \mathrm{P}$ plants. These data indicate the existence of an autoregulation mechanism managing the plastome-encoded phaseolin expression, whose mRNA translation is controlled by the amount of soluble phaseolin in the stroma (Figure 8).

\section{Discussion}

In this work, we have demonstrated that the translation of a recombinant phaseolin protein, whose gene is inserted in the tobacco plastome, is down-regulated by the presence in the stroma of soluble phaseolin polypeptides. Many chloroplastencoded proteins control their own production in C. reinhardtii and plants when the availability of their assembly partners is reduced (CES process), but this autoregulation has always been reported for polypeptides involved in the formation of heteromeric protein complexes. The stoichiometric imbalance of these complexes is the determinant for triggering the CES process, which affects only a limited number of proteins. Here we show that a negative feedback mechanism is able to regulate the translation in the stroma of a heterologous protein, which is not a part of any chloroplast endogenous heteromeric complexes. Therefore, autoregulation of translation in chloroplast can be also extended at least to the expression of some of the foreign proteins in transplastomic plants, and it is likely a more basic biological phenomenon than the previous belief. In particular, accumulation of mature phaseolin in the stroma of transplastomic plants is very low not due to polypeptide instability caused by protease degradation or alteration in protein folding (Figure 2), but because the translation of its mRNA is strongly reduced (Figure 4b). This inhibition occurs specifically on plastid ribosomes because when the same phaseolin protein, expressed from nuclear-transformed tobacco plants, is synthesized on cytoplasmic ribosomes and imported into the chloroplast, its accumulation significantly increased. Similarly, the $\mathrm{P}$ protein, which is the chloroplast-encoded full-length phaseolin, including its signal peptide, can reach accumulation levels comparable to that of the nuclear-encoded mutant (Figure 1c). This has been possible as 

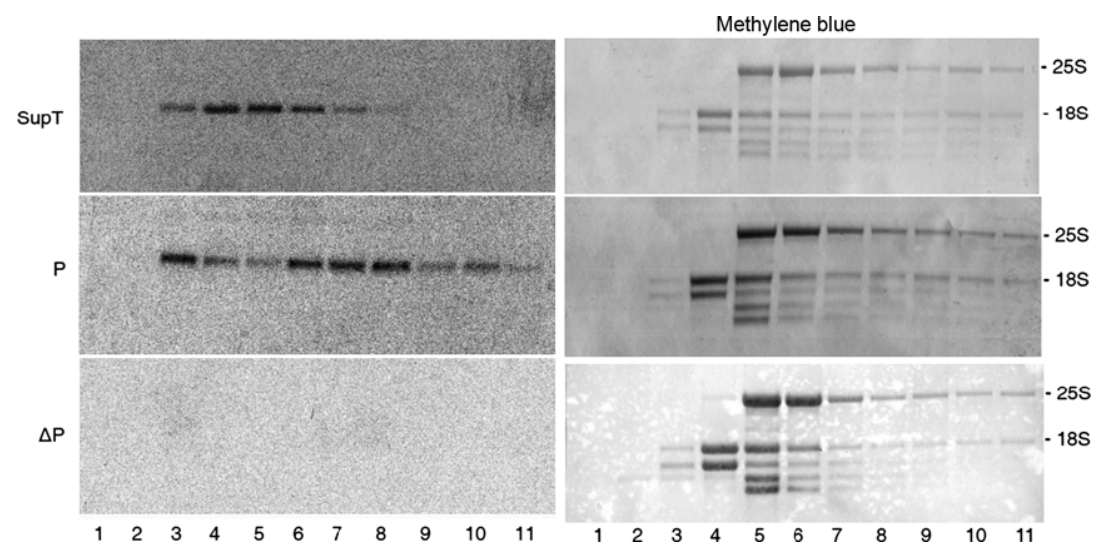

Figure 7 Polysome analysis in supertransformants (SupT) plants. Left panels: total leaf RNA from $\Delta \mathrm{P}, \mathrm{P}$ and SupT plants was fractionated through a $15 \%-55 \%$ sucrose gradient. The RNA present in the different fractions was extracted and analysed by northern blot with the phaseolin signal peptide sequence as a probe. Right panels: methylene blue staining is used to visualize the ribosomal RNA fractionation profile.

(a)

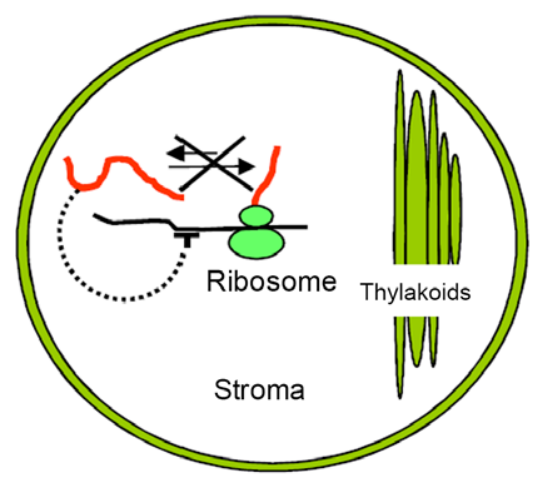

(b)

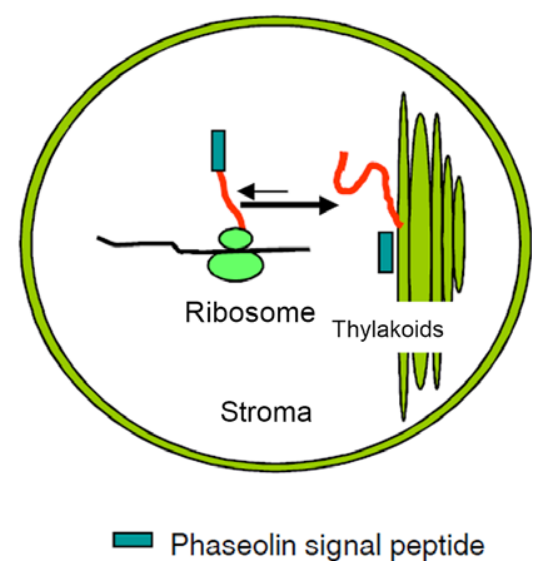

Figure 8 Schematic representation of the autoregulatory translation mechanism in tobacco chloroplast described in this study for phaseolin transgenes inserted into the plastome. (a) Negative regulatory feedback loop is revealed through repression of translation triggered by the presence of stromal phaseolin ( $\Delta \mathrm{P}$ transplastomic plants). (b) When they are synthesized together with their signal peptide, phaseolin polypeptides are targeted to the thylakoid membranes decreasing the amount of recombinant protein localized in the stroma, thus avoiding the activation of the autoregulatory translation mechanism. the phaseolin with the signal peptide is synthesized in the stroma but relocalized into the thylakoids after cleavage of the transit peptide (Figure 3), likely performed by the lumenal peptidase on the lumenal face of the thylakoid membrane. Considering that phaseolin does not have the physicochemical properties of an intrinsic membrane protein, we suggest that it has likely been translocated into the thylakoid lumen. Therefore, no matter which molecular determinant inhibits phaseolin translation in the chloroplast, this mechanism relies on the amount of soluble phaseolin in the stroma as a mode of activation. These results offer the interpretation for another report, where we observed that the accumulation of the zeolin fusion protein with phaseolin at the N-terminal was determined by its intraplastidial localization (De Marchis et al., 2011b). Reasonably, the scarcity of other transplastomic proteins could be attributed to autoregulation mechanisms, for example the human papillomavirus E7 antigen (Morgenfeld et al., 2014). To prove necessity of an excess over a threshold level of stromal phaseolin to induce its autoregulation, we supertransformed a P transplastomic plant with the nuclear phaseolin construct (expressing the chloroplast-targeted phaseolin). While the P mRNA was actively translated in transplastomic plants, in SupT $P$ transcript resulted to be less efficiently translated, indicating that in these plants the phaseolin accumulation in the chloroplast was almost exclusively due to the phaseolin polypeptides imported into the stroma from the cytosol (Figures 6 and 7). Moreover, this also means that the chloroplast translational regulation apparatus cannot distinguish between the phaseolin synthesized by the plastid ribosomes and the cytoplas- mic phaseolin. This last phaseolin is able to trigger the selfregulation mechanism that ultimately represses the synthesis of the P phaseolin protein. We ignore how this mechanism works and it may resemble the CES process in C. reinhardtii, where down-regulation of translation seems to be mediated by unidentified ternary translational activators capable of competitive binding to both the unassembled CES subunits and the $5^{\prime}$ untranslated region ( $5^{\prime} \cup T R$ ) of their corresponding mRNAs. In the transplastomic plants generated in this study, phaseolin Open reading frame (ORF) is fused to the tobacco psbA $5^{\prime} U T R$. The product of the chloroplast psbA gene is the PSII subunit D1, and in $C$. reinhardtii its decreased synthesis in the absence of protein assembly is due to inhibition of translation mediated by the $5^{\prime}$ UTR of its mRNA (Minai et al., 2006). Although D1, which has an amino acid sequence completely different from that of phaseolin, is not reported as a CES subunit in tobacco, it is still possible that a tobacco protein binding to both phaseolin and psbA $5^{\prime}$ UTRphaseolin transcript regulates heterologous phaseolin translation in the stroma. However, the psbA 5'UTR resulting in overexpression of several foreign proteins should also be considered (Verma and Daniell, 2007). We think that the here-suggested autoregulation machinery for phaseolin expression in the chloroplast could derive from a defence mechanism of bacterial origin. Horizontal gene transfer plays an important role in the evolution of bacteria; for example, it is responsible for antibiotic resistance transfer (Koonin et al., 2001). Horizontally transferred genes can either confer a selective advantage or result dangerous; therefore, bacteria have developed defence mechanisms like the bacterial nucleoid- 
associated protein $\mathrm{H}$-NS that transcriptionally represses horizontally acquired genes in Salmonella (Ali et al., 2013; Navarre et al., 2006). Thus, it is possible that the chloroplast has developed a biological system starting from an ancient defence pathway based on autorepressed translation of proteins that are soluble in the stroma (Figure 8). The CES feedback process may have evolved from this general regulation mechanism to coordinate the assembly of large heteromeric complexes. Recently, the existence of multiple negative regulatory feedback loops has been revealed in chloroplast, which compensates the decreased translation level or plastid mRNAs transcription in C. reinhardtii (Ramundo et al., 2013). In conclusion, we propose an autoregulation mechanism regulating heterologous protein accumulation in the stroma of transplastomic plants that is working for phaseolin and likely for other soluble heterologous proteins with low expression levels. This mechanism should be protein-specific considering that many foreign proteins have been hyperexpressed in the stroma of transplastomic plants thanks to their accumulation as insoluble aggregates (Kwon et al., 2013) and crystals (De Cosa et al., 2001), or due to the plant physiological adaptations (Bally et al., 2009).

\section{Experimental procedures}

\section{Growth conditions}

Nicotiana tabacum (cv. Petit Havana) was grown at $24{ }^{\circ} \mathrm{C}$ with a 16-h light/8-h dark period under $60 \mu \mathrm{E} / \mathrm{m} / \mathrm{s}^{2}$. Transplastomic plants were propagated on MSO medium supplemented with $500 \mathrm{mg} / \mathrm{L}$ spectinomycin. The nuclear transformants Pnu, tp $\Delta \mathrm{P}$ and SupT were maintained on MSO containing $50 \mathrm{mg} / \mathrm{L}$ kanamycin. T0 seeds were obtained from all the transgenics grown in the greenhouse. T1 plants were obtained after the germination of T0 seeds on agar-solidified MS medium plus $500 \mathrm{mg} / \mathrm{L}$ spectinomycin (transplastomic plants) or $50 \mathrm{mg} / \mathrm{L}$ kanamycin (Pnu, tp $\Delta \mathrm{P}$ plants) or 500 mg/L spectinomycin/50 mg/L kanamycin (SupT).

\section{Gene constructs and plant transformation}

The ORF of phaseolin was amplified from plasmid pDHA.T343F (Pedrazzini et al., 1997), digested with Ndel/Notl and cloned into pCR2.1-5'UTR (Watson et al., 2004), to obtain pCR2.15'UTR-P and pCR2.1-5'UTR- $\Delta \mathrm{P}$ (where the 72-bp phaseolin signal sequence was deleted) intermediate plasmids, in which the ORFs were under the $p s b A$ promoter $/ 5^{\prime} U T R$ control. The psbA/5'UTR-P and psbA/5'UTR- $\Delta \mathrm{P}$ cassettes were obtained by ECORV/Notl digestion of $p C R 2.1-5^{\prime} U T R-P$ and $p C R 2.1-5^{\prime} U T R-\Delta P$, respectively, and cloned into pLD-CTV (Dhingra et al., 2004), generating $\mathrm{pLD}-\mathrm{CTV}-\mathrm{P}$ and $\mathrm{pLD}-\mathrm{CTV}-\Delta \mathrm{P}$. Homoplasmic transplastomic plants were obtained as described (De Marchis et al., 2011b).

To prepare phaseolin with a transit peptide $(\mathrm{tp} \Delta \mathrm{P})$, the ORF coding for $\Delta \mathrm{P}$ was $\mathrm{PCR}$-amplified from $\mathrm{pCR} 2.1-5^{\prime} \mathrm{UTR}-\Delta \mathrm{P}$ using primers SphI $\triangle \mathrm{P} / E$ CORI $\Delta \mathrm{P}$-FLAG (this primer adds to the $\Delta \mathrm{P}$ C-terminus a Flag epitope), digested with Sphl/ECoRI and cloned into pJIT117 (Guerineau et al., 1988), containing the transit peptide of the tobacco Rubisco small subunit (SS). The tp $\Delta \mathrm{P}-\mathrm{FLAG}$ fragment, obtained by ECoRI/HindIII digestion of pJIT117.tp $\Delta \mathrm{P}-\mathrm{FLAG}$, was blunted by treatment with the Klenow fragment of DNA polymerase I and inserted into BamHI/blunted-linearized pDHA vector (Hellens et al., 2000), under the control of the $35 \mathrm{~S}$ promoter, obtaining pDHA.tp $\triangle \mathrm{P}-\mathrm{FLAG}$. The DNA fragment excised by $E C O R I$ digestion of $\mathrm{pDHA}$.tp $\triangle \mathrm{P}-\mathrm{FLAG}$, including the $35 \mathrm{~S}$ promoter, the tp $\triangle \mathrm{P}-\mathrm{FLAG}$ sequence and the $35 \mathrm{~S}$ terminator, was cloned into the EcoRl site of the pGreenll binary vector (Tabe et al., 1995), generating pGreenll.tp $\triangle \mathrm{P}-\mathrm{FLAG}$, which was introduced into the GV3101 strain of Agrobacterium tumefaciens. WT or pLD-CTV-P transplastomic plants were transformed as described (De Marchis et al., 2011a). The oligonucleotides used in this study were described in Table S1. Transgenic tobacco plants expressing phaseolin (Pnu) were obtained by seeds from Alessandro Vitale's laboratory.

\section{Protein analysis}

Total proteins were extracted from $0.3 \mathrm{~g}$ of leaves grounded in liquid nitrogen, homogenized in $0.8 \mathrm{~mL}$ of extraction buffer and analysed as reported previously (Bellucci et al., 2007), except for the antiphaseolin and anti-Rubisco antiserum which were diluted $1: 10000$ or $1: 7500$, respectively. When subjected to trypsin assay, protein aliquots of $8 \mu \mathrm{g}$ (Pnu and P plants) or $40 \mu \mathrm{g}(\Delta \mathrm{P})$ were digested for $30 \mathrm{~min}$ at $37^{\circ} \mathrm{C}$ with $10 \mu \mathrm{L}$ of trypsin (Roche Diagnostics $\mathrm{GmbH}$, Mannheim, Germany) from a $0.5 \mu \mathrm{g} / \mu \mathrm{L}$ solution in $\mathrm{HCl} 1 \mathrm{~mm}$, or with $10 \mu \mathrm{L}$ of $1 \mathrm{~mm} \mathrm{HCl}$ as control. The samples were transferred on ice to stop the digestion and then treated as described above.

Chloroplasts were isolated from $25 \mathrm{~g}$ batches of leaves and fractionated as described (Salvi et al., 2008), with minor modifications. Intact chloroplast was lysed and loaded on the top of a discontinuous sucrose gradient. The tubes were centrifuged at $70000 \mathbf{g}$ for $1 \mathrm{~h}$ and $4{ }^{\circ} \mathrm{C}$ to separate the soluble stromal proteins from the pelleted thylakoids. For further thylakoid purification, the pellet was washed with 10 volumes of washing buffer and centrifuged at $110000 \mathrm{~g}$ for $1 \mathrm{~h}$ and $4^{\circ} \mathrm{C}$ and then a minimum volume of washing buffer was added to the thylakoid pellet. To verify the association between thylakoids and proteins in the $P$ and $\Delta \mathrm{P}$ plants, the thylakoid pellet was washed with the washing buffer and centrifuged at $14000 \mathrm{~g}$ for $10 \mathrm{~min}$ and $4{ }^{\circ} \mathrm{C}$. The supernatant was recovered, the thylakoid pellet was washed again with the washing buffer plus $2 \mathrm{M} \mathrm{NaCl}$ and the saline supernatant was obtained by centrifugation. Chloroplast fractions were analysed by immunoblot assay using antiphaseolin antiserum (1: 10 000).

Alternatively, to isolate chloroplast fractions, another method was established by grinding in liquid nitrogen $300 \mathrm{mg}$ of leaf tissue and adding $1.2 \mathrm{~mL}$ of chloroplast lysis buffer [10 mm MOPS-NaOH, pH 7.8, 4 mm MgCl2, 1× protease inhibitor mix COMPLETE (Roche Diagnostics $\mathrm{GmbH}$ )]. The sample was divided in two aliquots of $0.6 \mathrm{~mL}$. To obtain the total sample, the first aliquot was supplemented with $1 \%$ Triton $\mathrm{X}-100$, vortexed and centrifuged at $12000 \mathbf{g}$ for $10 \mathrm{~min}$ and $4{ }^{\circ} \mathrm{C}$, and the supernatant was recovered. The second aliquot was freeze-thawed in liquid nitrogen and vortexed three times, supplemented with $2 \mathrm{M}$ $\mathrm{NaCl}$ and $0.5 \mathrm{~m} \mathrm{DTT}$, vortexed again and centrifuged at $12000 \mathrm{~g}$ for $10 \mathrm{~min}$ and $4{ }^{\circ} \mathrm{C}$ to obtain the soluble fraction. The pellet was resuspended in lysis buffer plus $1 \%$ Triton $\mathrm{X}-100$ and centrifuged at $12000 \mathrm{~g}$ for $10 \mathrm{~min}$ and $4{ }^{\circ} \mathrm{C}$ to obtain the membrane fraction. Chloroplast fractions were analysed by immunoblot assay using antiphaseolin (1: 10 000), anti-Flag (1: 1000; Sigma-Aldrich, St. Louis, MO), anti-Rubisco (1 : 7500; Jackson ImmunoResearch Inc., West Grove, PA) or anti-CP47 (1: 5000) antiserum. Protein band intensities (arbitrary units) were measured with the public-domain ImageJ software (US National Institute of Health, http://rsb.info.nih.gov/ij) on three independent immunoblots, using anti-Flag antibody, of soluble and membrane fractions in $\mathrm{P}, \mathrm{tp} \Delta \mathrm{P}$ and SupT tobacco plants. Other three independent measurements were obtained using antiphaseolin antibody. 
Velocity centrifugation on sucrose gradients was performed from young leaves of tobacco plants as described (Pompa et al., 2010), except that to increase the $\Delta P$ signal intensity on the Western blot, $0.60 \mathrm{~mL}$ of $\Delta \mathrm{P}$ leaf homogenate was loaded on the sucrose gradient, while $0.12 \mathrm{~mL}$ aliquots were used for the other plant samples.

\section{Gene expression analysis}

Total RNA was extracted with the GenEluteTM Plant Genomic DNA Kit (Sigma-Aldrich), and $2.5 \mu \mathrm{g}$ was analysed by northern blot as described (Bellucci et al., 2007). The phaseolin ORF was used as probe.

Polysomes were analysed from an extract prepared by grinding $300 \mathrm{mg}$ of leaf tissue in $1 \mathrm{~mL}$ of polysome extraction buffer as described (Barkan, 1993). The ORF of the phaseolin gene or its PCR-amplified 72-bp signal peptide sequence was used as probes.

\section{Protoplast preparation, pulse-chase labelling, immunoprecipitation and immunofluorescence}

Protoplasts were analysed as described by Pedrazzini et al. (1997), with minor modifications. Briefly, protoplasts were prepared from young tobacco leaves, subjected to pulse-chase labelling and, after overnight recovery, subjected to pulse-chase labelling with Pro-Mix (a mixture of [35S]Met and [35S]Cys; GE Healthcare Little Chalfont, Buckinghamshire, United Kingdom). Homogenization of the protoplasts was performed by adding to frozen samples protoplast homogenation buffer (150 mM Tris-Cl, $\mathrm{pH} 7.5,150 \mathrm{~mm} \mathrm{NaCl}, 1.5 \mathrm{~mm}$ EDTA, 1.5\% Triton X-100 and Complete protease inhibitor cocktail [Roche]). Proteins were immunoselected using rabbit polyclonal antisera against phaseolin. The immunoprecipitates were analysed by SDS-PAGE. After electrophoresis, gels were treated with AmplifyTM fluorography reagent (GE Healthcare), dried and exposed for fluorography. When treated with $\mathrm{CHX}$, protoplasts were supplemented before the pulse with $10 \mu \mathrm{g} / \mathrm{mL}$ of the antibiotic for $30 \mathrm{~min}$. Aliquots of untreated protoplasts from the same protoplast preparation were used to extract and analyse total proteins as described in the paragraph 'Protein analysis', except for the extraction buffer to which $1 \%$ Triton $\mathrm{X}-100$ was added.

After overnight recovery, protoplasts were fluorescencelabelled according to Frigerio et al. (2001) with minor modifications. Protoplasts were treated with antiphaseolin (1: 10 000) antiserum, and the primary antibody was detected using fluorescein isothiocyanate-conjugated (FITC) anti-rabbit secondary antibody at 1 : 200 dilution (Jackson Immunoresearch). Cells were visualized with a Zeiss PALM Microbeam Axio-observer.Z1 fluorescence microscope equipped with a $63 \times$ oil immersion objective. Images were collected with an AxioCam MRm 60N-C 1"1, ox camera (Zeiss, Oberkochen, Germany) and visualized with Axiovision software.

\section{Acknowledgements}

We thank Alessandro Vitale for kindly providing antibodies against phaseolin protein and Stefano Cristiani for technical assistance.

\section{Conflict of interest}

The authors declare that they do not have any conflict of interest.

\section{References}

Ali, S.S., Whitney, J.C., Stevenson, J., Robinson, H., Howell, P.L. and Navarre, W.W. (2013) Structural insights into the regulation of foreign genes in Salmonella by the Hha/H-NS complex. J. Biol. Chem. 10, 13356-13369.

Ahmad, N., Michoux, F. and Nixon, P.J. (2012) Investigating the production of foreign membrane proteins in tobacco chloroplasts: expression of an algal plastid terminal oxidase. PLOS ONE, 7, e41722

Bally, J., Paget, E., Droux, M., Job, C., Job, D. and Dubald, M. (2008) Both the stroma and thylakoid lumen of tobacco chloroplasts are competent for the formation of disulphide bonds in recombinant proteins. Plant Biotechnol. J. 6 , 46-61.

Bally, J., Nadai, M., Vitel, M., Rolland, A., Dumain, R. and Dubald, M. (2009) Plant physiological adaptations to the massive foreign protein synthesis occurring in recombinant chloroplasts. Plant Physiol. 150, 1474-1481.

Barkan, A. (1993) Nuclear mutants of maize with defects in chloroplast polysome assembly have altered chloroplast RNA metabolism. Plant Cell, 5, 389-402.

Barkan, A. and Small, I. (2014) Pentatricopeptide repeat proteins in plants. Annu. Rev. Plant Biol. 65, 415-442.

Bellucci, M., De Marchis, F., Mannucci, R., Bock, R. and Arcioni, S. (2005) Cytoplasm and chloroplasts are not suitable subcellular locations for b-zein accumulation in transgenic plants. J. Exp. Bot. 56, 1205-1212.

Bellucci, M., De Marchis, F., Nicoletti, I. and Arcioni, S. (2007) Zeolin is a recombinant storage protein with different solubility and stability properties according to its localization in the endoplasmic reticulum or in the chloroplast. J. Biotechnol. 131, 97-105.

Birch-Machin, I., Newell, C.A., Hibberd, J.M. and Gray, J.C. (2004) Accumulation of rotavirus VP6 protein in chloroplasts of transplastomic tobacco is limited by protein stability. Plant Biotechnol. J. 2, 261-270.

Bock, R. and Warzecha, H. (2010) Solar-powered factories for new vaccines and antibiotics. Trends Biotechnol. 28, 246-252.

Bock, R. (2014) Genetic engineering of the chloroplast: novel tools and new applications. Curr. Opin. Biotechnol. 26, 7-13.

Boulouis, A., Raynaud, C., Bujaldon, S., Aznar, A., Wollman, F.A. and Choquet, Y. (2011) The nucleus-encoded trans-acting factor MCA1 plays a critical role in the regulation of cytochrome $\mathrm{f}$ synthesis in Chlamydomonas chloroplasts. Plant Cell, 23, 333-349.

Daniell, H. (2006) Production of biopharmaceuticals and vaccines in plants via the chloroplast genome. Biotechnol. J. 1, 1071-1079.

De Cosa, B., Moar, W., Lee, S.B., Miller, M. and Daniell, H. (2001) Overexpression of the Bt cry2Aa2 operon in chloroplasts leads to formation of insecticidal crystals. Nat. Biotechnol. 19, 71-74.

De Marchis, F., Balducci, C., Pompa, A., Riise Stensland, H.M., Guaragno, M. Pagiotti, R., Menghini, A.R., Persichetti, E., Beccari, T. and Bellucci, M. (2011a) Human $\alpha$-mannosidase produced in transgenic tobacco plants is processed in human $\alpha$-mannosidosis cell lines. Plant Biotechnol. J. 9, 1061-1073.

De Marchis, F., Pompa, A., Mannucci, R., Morosinotto, T. and Bellucci, M. (2011b) A plant secretory signal peptide targets plastome-encoded recombinant proteins to the thylakoid membrane. Plant Mol. Biol. 76, 427-441.

De Marchis, F., Pompa, A. and Bellucci, M. (2012) Plastid proteostasis and heterologous protein accumulation in transplastomic plants. Plant Physiol. 160, 571-581.

Deshpande, S.S. and Nielsen, S.S. (1987) In vitro enzymatic hydrolysis of phaseolin, the major storage protein of Phaseolus vulgaris L. J. Food Sci. 52, 1326-1329

Dhingra, A., Portis, A.R. Jr and Daniell, H. (2004) Enhanced translation of a chloroplast-expressed RbcS gene restores small subunit levels and photosynthesis in nuclear RbcS antisense plants. Proc. Natl Acad. Sci. USA, 20, 6315-6320.

Drapier, D., Rimbault, B., Vallon, O., Wollman, F.A. and Choquet, Y. (2007) Intertwined translational regulations set uneven stoichiometry of chloroplast ATP synthase subunits. EMBO J. 8, 3581-3591.

Elghabi, Z., Karcher, D., Zhou, F., Ruf, S. and Bock, R. (2011) Optimization of the expression of the HIV fusion inhibitor cyanovirin- $\mathrm{N}$ from the tobacco plastid genome. Plant Biotechnol. J. 9, 599-608. 
Fontanesi, F., Soto, I.C., Horn, D. and Barrientos, A. (2010) Mss51 and Ssc1 facilitate translational regulation of cytochrome c oxidase biogenesis. Mol. Cell. Biol. 30, 245-259.

Frigerio, L., de Virgilio, M., Prada, A., Faoro, F. and Vitale, A. (1998) Sorting of phaseolin to the vacuole is saturable and requires a short C-terminal peptide. Plant Cell, 10, 1031-1042.

Frigerio, L., Pastres, A., Prada, A. and Vitale, A. (2001) Influence of KDEL on the fate of trimeric or assembly defective phaseolin: selective use of an alternative route to vacuoles. Plant Cell, 13, 1109-1126.

Guerineau, F., Woolston, S., Brooks, L. and Mullineaux, P. (1988) An expression cassette for targeting foreign proteins into chloroplasts. Nucleic Acids Res. 9, 11380.

Hellens, R.P., Edwards, E.A., Leyland, N.R., Bean, S. and Mullineaux, P.M. (2000) pGreen: a versatile and flexible binary Ti vector for Agrobacteriummediated plant transformation. Plant Mol. Biol. 42, 819-832.

Hennig, A., Bonfig, K., Roitsch, T. and Warzecha, H. (2007) Expression of the recombinant bacterial outer surface protein $A$ in tobacco chloroplasts lead to thylakoid localization and loss of photosynthesis. FEBS J. 274, 57495758.

Jutras, B.L., Jones, G.S., Verma, A., Brown, N.A., Antonicello, A.D., Chenail, A.M. and Stevenson, B. (2013) Posttranscriptional self-regulation by the Lyme disease bacterium's BpuR DNA/RNA-binding protein. J. Bacteriol. 195, 49154923.

Koonin, E.V., Makarova, K.S. and Aravind, L. (2001) Horizontal gene transfer in prokaryotes: quantification and classification. Annu. Rev. Microbiol. 55, 709742.

Kuroda, H. and Maliga, P. (2001) Complementarity of the 16S rRNA penultimate stem with sequences downstream of the AUG destabilizes the plastid mRNAs. Nucleic Acids Res. 29, 970-975.

Kwon, K.C., Verma, D., Singh, N.D., Herzog, R. and Daniell, H. (2013) Oral delivery of human biopharmaceuticals, autoantigens and vaccine antigens bioencapsulated in plant cells. Adv. Drug Deliv. Rev. 65, 782799.

Lentz, E.M., Garaicoechea, L., Alfano, E.F., Parreño, V., Wigdorovitz, A. and Bravo-Almonacid, F.F. (2012) Translational fusion and redirection to thylakoid lumen as strategies to improve the accumulation of a camelid antibody fragment in transplastomic tobacco. Planta, 236, 703-714.

Levey, T., Westhoff, P. and Meierhoff, K. (2014) Expression of a nuclearencoded psbH gene complements the plastidic RNA processing defect in the PSII mutant hcf107 in Arabidopsis thaliana. Plant J. 80, 292-304.

Manuell, A.L., Quispe, J. and Mayfield, S.P. (2007) Structure of the chloroplast ribosome: novel domains for translation regulation. PLOS Biol. 5, e209.

Minai, L., Wostrikoff, K., Wollman, F.A. and Choquet, Y. (2006) Chloroplast biogenesis of photosystem II cores involves a series of assembly-controlled steps that regulate translation. Plant Cell, 18, 159-175.

Michelet, L., Lefebvre-Legendre, L., Burr, S.E., Rochaix, J. and GoldschmidtClermont, M. (2010) Enhanced chloroplast transgene expression in a nuclear mutant of Chlamydomonas. Plant Biotechnol. J. 9, 565-574.

Morgenfeld, M., Lentz, E., Segretin, M.E., Alfano, E.F. and Bravo-Almonacid, F. (2014) Translational fusion and redirection to thylakoid lumen as strategies to enhance accumulation of human papillomavirus e7 antigen in tobacco chloroplasts. Mol. Biotechnol. 56, 1021-1031.

Navarre, W.W., Porwollik, S., Wang, Y., McClelland, M., Rosen, H., Libby, S.J. and Fang, F.C. (2006) Selective silencing of foreign DNA with low GC content by the H-NS protein in Salmonella. Science, 14, 236-238.

Oey, M., Lohse, M., Kreikemeyer, B. and Bock, R. (2009) Exhaustion of the chloroplast protein synthesis capacity by massive expression of a highly stable protein antibiotic. Plant J. 57, 436-445.

Pedrazzini, E., Giovinazzo, G., Bielli, A., de Virgilio, M., Frigerio, L., Pesca, M., Faoro, F., Bollini, R., Ceriotti, A. and Vitale, A. (1997) Protein quality control along the route to the plant vacuole. Plant Cell, 9, 1869-1880.

Pompa, A., De Marchis, F., Vitale, A., Arcioni, S. and Bellucci, M. (2010) An engineered C-terminal disulfide bond can partially replace the phaseolin vacuolar sorting signal. Plant J. 61, 782-791.

Ramundo, S., Rahire, M., Schaad, O. and Rochaix, J.D. (2013) Repression of essential chloroplast genes reveals new signaling pathways and regulatory feedback loops in chlamydomonas. Plant Cell, 25, 167-186.
Ruhlman, T., Verma, D., Samson, N. and Daniell, H. (2010) The role of heterologous chloroplast sequence elements in transgene integration and expression. Plant Physiol. 152, 2088-2104.

Salvi, D., Rolland, N., Joyard, J. and Ferro, M. (2008) Purification and proteomic analysis of chloroplasts and their sub-organellar compartments. Methods Mol. Biol. 432, 19-36.

Scotti, N., Bellucci, M. and Cardi, T. (2013) The chloroplasts as platform for recombinant proteins production. In Translation in Mitochondria and Other Organelle (Duchêne, A.-M., ed.), pp. 225-262. Berlin Heidelberg: SpringerVerlag.

Shanmugabalaji, V., Besagni, C., Piller, L.E., Douet, V., Ruf, S., Bock, R. and Kessler, F. (2013) Dual targeting of a mature plastoglobulin/fibrillin fusion protein to chloroplast plastoglobules and thylakoids in transplastomic tobacco plants. Plant Mol. Biol. 81, 13-25.

Shiina, T., Tsunoyama, Y., Nakahira, Y. and Khan, M.S. (2005) Plastid RNA polymerases, promoters, and transcription regulators in higher plants. Int. Rev. Cytol. 244, 1-68.

Singh, N.D., Li, M., Lee, S.B., Schnell, D. and Daniell, H. (2008) Arabidopsis Tic40 expression in tobacco chloroplasts results in massive proliferation of the inner envelope membrane and upregulation of associated proteins. Plant Cell, 20, 3405-3417.

Stern, D.B., Goldschmidt-Clermont, M. and Hanson, M.R. (2010) Chloroplast RNA metabolism. Annu. Rev. Plant Biol. 61, 125-155.

Suzuki, Y. and Makino, A. (2013) Translational downregulation of RBCL is operative in the coordinated expression of Rubisco genes in senescent leaves in rice. J. Exp. Bot. 64, 1145-1152.

Tabe, L.M., Wardley-Richardson, T., Ceriotti, A., Aryan, A., McNabb, W., Moore, A. and Higgins, T.J. (1995) A biotechnological approach to improving the nutritive value of alfalfa. J. Anim. Sci. 73, 2752-2759.

Tangphatsornruang, S., Birch-Machin, I., Newell, C.A. and Gray, J.C. (2011) The effect of different $3^{\prime}$ untranslated regions on the accumulation and stability of transcripts of a gfp transgene in chloroplasts of transplastomic tobacco. Plant Mol. Biol. 76, 385-396.

Tiller, N. and Bock, R. (2014) The translational apparatus of plastids and its role in plant development. Mol. Plant, 7, 1105-1120.

Timmis, J.N., Ayliffe, M.A., Huang, C.Y. and Martin, W. (2004) Endosymbiotic gene transfer: organelle genomes forge eukaryotic chromosomes. Nat. Rev. Genet. 5, 123-135.

Verma, D. and Daniell, H. (2007) Chloroplast vector systems for biotechnology applications. Plant Physiol. 145, 1129-1143.

Verma, D., Moghimi, B., LoDuca, P.A., Singh, H.D., Hoffman, B.E., Herzog, R.W. and Daniell, H. (2010) Oral delivery of bioencapsulated coagulation factor IX prevents inhibitor formation and fatal anaphylaxis in hemophilia B mice. Proc. Natl Acad. Sci. USA, 107, 7101-7106.

de Virgilio, M., De Marchis, F., Bellucci, M., Mainieri, D., Rossi, M., Benvenuto, E., Arcioni, S. and Vitale, A. (2008) The human immunodeficiency virus antigen Nef forms protein bodies in leaves of transgenic tobacco when fused to zeolin. J. Exp. Bot. 59, 2815-2829.

Vitale, A., Bielli, A. and Ceriotti, A. (1995) The binding protein associates with monomeric phaseolin. Plant Physiol. 107, 1411-1418.

Watson, J., Koya, V., Leppla, S.H. and Daniell, H. (2004) Expression of Bacillus anthracis protective antigen in transgenic chloroplasts of tobacco, a nonfood/feed crop. Vaccine, 22, 4374-4384.

Wirth, S., Segretin, M.E., Mentaberry, A. and Bravo-Almonacid, F. (2006) Accumulation of hEGF and hEGF-fusion proteins in chloroplast-transformed tobacco plants is higher in the dark than in the light. J. Biotechnol. 125, 159-172.

Woodson, J.D. and Chory, J. (2008) Coordination of gene expression between organellar and nuclear genomes. Nat. Rev. Genet. 9, 383-395.

Wostrikoff, K., Girard-Bascou, J., Wollman, F.A. and Choquet, Y. (2004) Biogenesis of PSI involves a cascade of translational autoregulation in the chloroplast of Chlamydomonas. EMBO J. 7, 2696-2705.

Wostrikoff, K. and Stern, D. (2007) Rubisco large-subunit translation is autoregulated in response to its assembly state in tobacco chloroplasts. Proc. Natl Acad. Sci. USA, 10, 6466-6471.

Wostrikoff, K., Clark, A., Sato, S., Clemente, T. and Stern, D. (2012) Ectopic expression of Rubisco subunits in maize mesophyll cells does not overcome barriers to cell type-specific accumulation. Plant Physiol. 160, $419-432$. 
Yang, H., Gray, B.N., Ahner, B.A. and Hanson, M.R. (2013) Bacteriophage 5' untranslated regions for control of plastid transgene expression. Planta, 237 517-527.

Ye, G.N., Hajdukiewicz, P.T., Broyles, D., Rodriguez, D., Xu, C.W., Nehra, N and Staub, J.M. (2001) Plastid expressed 5-enolpyruvylshikimate-3-phosphate synthase genes provide high level glyphosate tolerance in tobacco. Plant $J$. 25, 261-270.

Zoschke, R., Watkins, K.P. and Barkan, A. (2013) A rapid ribosome profiling method elucidates chloroplast ribosome behavior in vivo. Plant Cell, 25 2265-2275.

\section{Supporting information}

Additional Supporting information may be found in the online version of this article:
Figure $\mathbf{S} 1$ Chloroplast localization of $\operatorname{tp} \Delta \mathrm{P}, \mathrm{P}$, and $\Delta \mathrm{P}$ proteins. Figure S2 Analysis of the correct transgene insertion in supertransformed (SupT) tobacco plants.

Figure S3 Absence of phaseolin polypeptides in the immunoprecipitation supernatant fractions.

Figure S4 Tridimensional conformation of $\operatorname{tp} \Delta \mathrm{P}$ and SupT phaseolins in the chloroplast.

Table S1 Oligonucleotides used in this study. 